\title{
Environmental Health Science at the U.S. Geological Survey
}

A healthy environment provides abundant social, economic, and public benefits. Environmentally driven disease caused by exposure to toxic substances and pathogens can threaten public health and the health of our Nation's natural resources. U.S. Geological Survey (USGS) environmental health science focuses on the interface between health and the environment, where interactions among people, the environment, and other living organisms affect the risk of toxicologic and infectious disease. USGS science provides the foundation for decisionmaking by resource managers, policy makers, regulators, industry, and the public.

\section{USGS and Environmental Health Science}

Interactions among the quality of the physical environment, the health of living resources, and human health are driven by both human activities and natural earth processes (fig. 1). Changes in the environment affect the health of people and wild and domesticated animals. Changes in the health and abundance of wild and domesticated animals affect human health and wellbeing. Societal demands for land, natural resources, quality of life, and economic prosperity lead to environmental change. Natural earth processes (such as weathering, runoff, wind, climate trends, and natural hazards) compound those effects. These environmental drivers affect exposure to contaminants (natural earth materials, toxins, and synthetic chemicals and substances) and pathogens (viruses, bacteria, protozoa, fungi, parasites, and prions), and influence susceptibility to a wide variety of environmental disease (fig. 2).

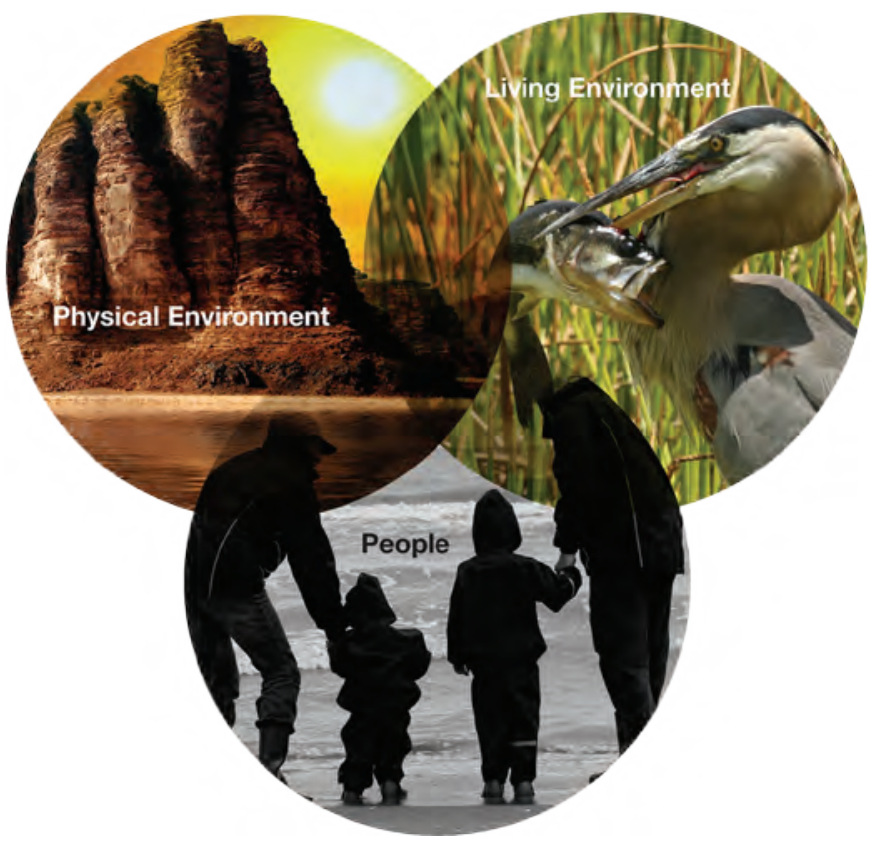

Figure 1. The USGS defines environmental health science as the study of the interrelations among the quality of the physical environment, the health of the living environment (all organisms except people), and the health of people (human health).
USGS environmental health science focuses on the environment-health interface. Research characterizes the processes that affect the interaction among the physical environment, the living environment, and people, and the resulting factors that affect ecological and human exposure to disease agents and the resulting toxicologic or infectious disease.

\section{The USGS Environmental Health Science Strategy}

The USGS is a Federal science agency that provides a broad range of natural science information as the basis for sound management and policy decisions. In 2012, USGS published an environmental health science strategy, one of seven science strategies that span the breadth of USGS science. It summarizes national environmental health priorities that USGS is best suited to address, and will serve as a strategic framework for USGS environmental health science goals, actions, and outcomes for the next decade. Implementation of this strategy will aid the coordination of USGS environmental health activities with those of other Federal agencies and provide a focal point for disseminating information to stakeholders.

Vision-The USGS is a premier source of the environmental health science needed to safeguard the health of the environment, fish and wildlife, domesticated animals, and people.

Mission - The mission of USGS in environmental health science is to contribute scientific information to environmental, natural resource, agricultural, and public-health managers, who use that information to support sound decisionmaking. USGS will provide science to achieve the following societal goals:

- Goal 1-Identify, prioritize, and detect contaminants and pathogens of emerging environmental concern.

- Goal 2-Reduce the impact of contaminants on the environment, fish and wildlife, domesticated animals, and people.

- Goal 3-Reduce the impact of pathogens on the environment, fish and wildlife, domesticated animals, and people.

- Goal 4-Discover the complex interactions between, and combined effects of, exposure to contaminants and pathogens.

- Goal 5-Prepare for and respond to the environmental impacts and related health threats of natural and anthropogenic disasters. 


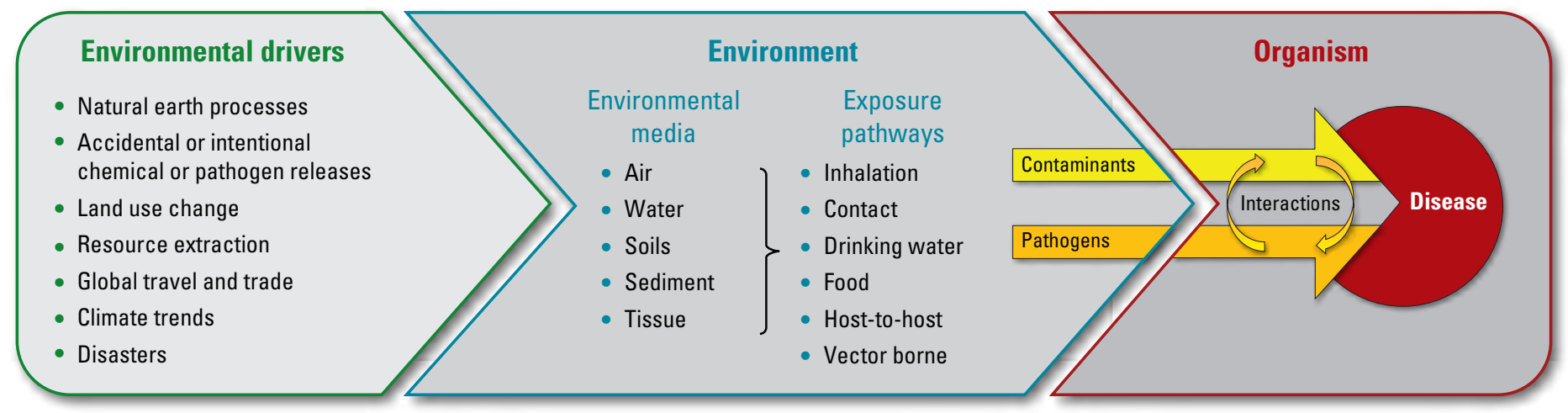

Figure 2. The USGS Environmental Health Science Strategy addresses the relations among environmental drivers, exposure to disease agents (contaminants and pathogens) through various media and exposure pathways, and the complex responses to contaminant and pathogen exposure that result in environmental disease in organisms, including fish and wildlife, domesticated animals, and people.

\section{USGS Environmental Health Science Activities}

USGS environmental health science activities:

- Are at the forefront of identifying wild animal disease reservoirs and the sources of emerging contaminants;

- Monitor the quality of the environment and the health of fish and wildlife at local, regional, and national scales;

- Define the factors that control the ecology of infectious diseases that affect natural populations of aquatic and terrestrial species.

- Synthesize critical knowledge about disease transmission, including to domesticated animals, and humans;

- Identify the environmental properties and ecological effects of natural and anthropogenic contaminants;

- Characterize potential human exposure to contaminants through drinking and recreational water, consumption of fish and wildlife, and inhalation of or contact with air, dust, soil, and sediment; and

- Synthesize, analyze and interpret environmental data in a geospatial context.

\section{Intended Outcome}

The intended outcome of this science strategy is the prevention and reduction of the adverse impacts of toxicologic and infectious disease. USGS science will help: (1) focus research and management on the prevention of future environmental health threats; (2) improve management, remediation, and restoration of contaminated environments; (3) reduce the spread of infectious disease among free-ranging populations of aquatic and terrestrial organisms, domesticated animals, and humans; and (4) characterize the complex interactions and combined effects of contaminants and pathogens.

Communication with partners and stakeholders regarding science needs and priorities is essential for successful implementation of the strategy. Coordination with partners and stakeholders will enable USGS to focus on the highest priority environmental health issues, to make relevant, timely, and useable contributions, and to become a "partner of first choice" for environmental health science.
The health and abundance of aquatic species can be affected by toxic substances and pathogens, which in turn have economic and human health consequences.

\section{For more information on the USGS:}

- Environmental Health Science Strategy-http://pubs.usgs.gov/circ/1383e/

- Environmental Health Newsletter-http://health.usgs.gov/geohealth/

- Environmental Health Science Webpage-http://www.usgs.gov/envirohealth/ 